\title{
PEDAGOGÍA HOSPITALARIA. PRESENTACIÓN
}

\section{Hospital Pedagogy. Presentation}

\author{
M. a Isabel Calvo Álvarez
}

$\mathrm{E}$

N eSte monográfico nos acercamos al ámbito de la Pedagogía Hospitalaria, sus orígenes, principios, objetivos y metodologías. En él quedan abiertos interrogantes para seguir trabajando: ¿Cuál es el futuro de la Pedagogía Hospitalaria, existen limitaciones? ¿De dónde surgen? ¿Cómo mejorar la estancia en el hospital para el niño, para su familia y para otros pacientes? ¿Qué necesitan las plantas del establecimiento sanitario, el aula hospitalaria y los profesionales?

En las ultimas décadas, como consecuencia de los avances en la medicina y en la educación, han cambiado los modelos de atención al niño enfermo y hospitalizado y se ha permitido la incorporación en los hospitales de otros profesionales no pertenecientes al ámbito sanitario, que contribuyen de forma eficaz a la atención integral al niño hospitalizado. Cada vez son más frecuentes los estudios que se centran en la intervención educativa en los hospitales, interés recogido tanto en las políticas educativas como en las sanitarias.

Este trabajo ha sido posible gracias a la participación de profesionales que han aportado conocimiento, experiencias y propuestas de cómo transformar las prácticas, la formación, la organización y los recursos para mejorar la atención al niño enfermo y hospitalizado y ampliar el campo de acción de la Pedagogía Hospitalaria.

Los dos primeros artículos abordan las bases teóricas de la Pedagogía Hospitalaria, sus objetivos, el derecho a la educación, los principios de intervención y el valor de la acción educativa en el aula hospitalaria.

A continuación se presenta un estudio de caso centrado en el funcionamiento de las unidades pedagógicas hospitalarias de la Comunidad Valenciana. El objetivo principal de la UPH es normalizar su vida y asegurar que los niños no olviden lo que son, para lo cual han implementado en el Servicio de Oncología Pediátrica un proyecto educativo, a través de un cuento La cebra Camila, con gran cantidad de actividades y recursos didácticos.

¿Payasos y hospital un tándem inseparable? El siguiente artículo se centra en una investigación que tiene como objetivo comprobar si el uso del humor como estrategia activa para afrontar la enfermedad es eficaz en los niños oncológicos y sus familias. Afirmando, una vez analizados los datos, que la intervención de los Terapiclowns es recomendable y positiva. Se destaca que el empleo del humor no soluciona ningún problema en sí mismo, pero puede cambiar la forma de abordar la enfermedad y por tanto constituye una estrategia activa para afrontarla. 
Desde la Universidad de las Islas Baleares nos llega el proyecto INeDiTHos, iniciado en 2003, que tiene como finalidad trabajar para la mejora de la calidad de vida de niños y jóvenes con enfermedades raras a partir de la intervención e investigación con voluntariado universitario. Dicho proyecto ha acercado las Enfermedades Raras a la comunidad universitaria a través de la metodología de Aprendizaje Servicio.

Desde Venezuela se describe la evolución de atención al niño enfermo, el surgimiento de las aulas hospitalarias y los programas y proyectos que se realizan en el país, deteniéndose en la formación de los profesionales en Pedagogía Hospitalaria.

Finalmente, se presenta un estudio que analiza la formación de los profesores de las aulas hospitalarias en el contexto brasileño, concluyendo que a día de hoy falta una política pública que oriente la formación inicial y continua respondiendo a las necesidades de los profesores hospitalarios. El estudio pone de manifiesto carencias en su formación.

Son muchos los programas, proyectos y actividades a corto, medio y largo plazo que se han implementado en el hospital con el fin de mejorar la calidad de vida del niño hospitalizado. Es necesario disponer de recursos y de mayor dotación de profesionales para ofrecer una atención global al menor y sus familias. Poner en marcha proyectos educativos como complemento a las actividades de salud y crear un equipo de intervención multiprofesional que se haga cargo de la orientación, apoyo, asesoramiento, información, formación... a todos los implicados en el proceso.

La Pedagogía Hospitalaria cada vez más tiene un gran protagonismo en la atención al niño enfermo y en el hospital. Mejorarlo es nuestro reto y nuestro compromiso. 